\title{
Cognition in Late-Life Depression: Treatment Considerations
}

\author{
Aaron M. Koenig, $M D^{1,2}$ \\ Meryl A. Butters, PhD ${ }^{1,2, *}$
}

\author{
1, Western Psychiatric Institute and Clinic, 3811 O'Hara Street \\ Pittsburgh, PA 15213, USA \\ Email:ButtersMA@upmc.edu \\ ${ }^{2}$ Department of Psychiatry, University of Pittsburgh School of Medicine, \\ Pittsburgh, PA 15213, USA
}

Published online: 5 December 2013

(C) Springer International Publishing AG 2013

Keywords Late-life depression · Mild cognitive impairment - Dementia - Treatment - Antidepressant · Cognitive training - Pharmacotherapy . Psychotherapy - Electroconvulsive therapy - Emerging treatments

\section{Opinion statement}

Late-life depression (LLD) frequently presents with cognitive impairment, and growing evidence suggests that these disease processes are "linked" in multiple ways. For some individuals, LLD may be a recurrence of a long-standing depressive illness, while for others it may be the leading symptom of a developing neuropathological disorder. Overall, studies investigating the relationship between the treatment of LLD and improvement in cognitive functioning have yielded mixed results. Research suggests that a subset of individuals with LLD and cognitive dysfunction will experience an improvement in cognitive function after antidepressant treatment, though a significant proportion will continue to exhibit cognitive impairment following resolution of their depressive symptoms. From a treatment standpoint, it is critical to ensure that an individual's depressive symptoms have been treated to remission, measured by a standardized rating scale such as the Geriatric Depression Scale (GDS). Selective serotonin reuptake inhibitor (SSRI) or serotonin-norepinephrine reuptake inhibitor (SNRI) monotherapy is often effective, and may be enhanced by employing an evidence-based psychotherapy such as Problem-Solving Therapy (PST) or Interpersonal Therapy (IPT), modified to accommodate cognitive impairments that may be present. With respect to specific treatment of cognitive dysfunction, cognitive augmentation or training strategies can be helpful for some patients, and may be explored in combination with treatment of the primary depressive episode. While the introduction of a cholinesterase inhibitor (e.g., donepezil) may be considered, the potential benefit (modest improvement in cognition and functioning) must be weighed against an increased risk for worsening or recurrent depression. Finally, lifestyle factors-such as aerobic exercise, follow-up with a primary care physician for management of co-morbid medical illnesses, and regular participation in stimulating activities (such as through a senior center)-are important and should be included as part of the overall treatment plan. 


\section{Introduction}

Late-life depression (LLD), defined as a major depressive episode occurring in an older adult (60 years or older), encompasses both late-onset cases and earlyonset cases that recur or continue into the later years of life. In the clinical setting, patients with LLD frequently present with cognitive complaints, and 20$50 \%$ of individuals with LLD are estimated to have cognitive impairment greater than that of age- and education-matched, never-depressed control subjects [ 1 , 2]. Cognitive deficits in LLD, which include impairments in episodic memory, speed of information processing, executive functioning, and visual-spatial ability [1-7], have been associated with increased rates of depression relapse, poor response to antidepressant treatment, and greater overall disability. Of the cognitive domains that are often affected, information processing speed and executive functioning appear to be particularly vulnerable, and several studies have reported that overall cognitive impairment associated with LLD appears to be predominantly mediated by slowed speed of information processing and/or working memory deficits.

From a diagnostic perspective, LLD is often under-reported, under-recognized, misdiagnosed, and under-treated [8], due in part to characteristics that set it apart from earlier-onset depression (i.e., depression that presents before age 60). Compared to younger adults, individuals with LLD are less likely to present with sadness or dysphoria [9] and are more likely to exhibit agitation or somatic symptoms such as gastrointestinal distress, insomnia, or fatigue [10]. In addition, while earlier-onset depression is more prevalent in women, such gender differences are greatly reduced in LLD [11]. LLD is also generally more chronic and difficult to treat to remission than earlier-onset depression, an observation that has been attributed in part to medical co-morbidity and co-occurring cognitive dysfunction [12]. For these reasons and others, LLD is associated with significant mortality, healthcare utilization, physical disability, and functional decline in older adults [13-15].

A complex relationship exists between the treatment of LLD and improvement (or resolution) of cognitive symptoms. Studies suggest that a subset of individuals with LLD and cognitive dysfunction may demonstrate an improvement in cognition after antidepressant treatment [16], though a significant proportion will continue to experience cognitive impairment following resolution of depressive symptoms [17-22]. Certain risk factors, including lower baseline cognition, older age, later age of depression onset, and greater vascular burden, have been associated with less cognitive improvement after antidepressant treatment [23]. In the following sections, we present an overview of current treatment options for the management of cognitive dysfunction in LLD.

\section{Treatment}

\section{Diet and lifestyle}

- Diet and lifestyle modifications may play a positive role in the management of older adults with depression and cognitive dysfunction. Healthcare providers should encourage:

- An assessment by a dietician to ensure adequate caloric intake, evaluate the need for vitamin supplementation (especially for frail and medically-complex patients), and recommend dietary changes that may enhance vascular health (e.g., Mediterranean diet)

- Driver skill assessment, with driving restrictions if appropriate $[24,25]$ 
- Family members and caregivers as active members of the treatment team

- Regular follow-up with a primary care physician:

Cognitive and depressive burden are closely related to physical health. With this in mind, it is important that patients maintain close follow-up with a primary care physician who can facilitate guideline-based management of co-morbid medical conditions-such as diabetes, hypertension, and heart disease-that are known to have a deleterious effect on mood and cognition [26].

If available, a collaborative-care model is encouraged (e.g., a mental health "care-manager" partnering with a primary care practice). In addition to ensuring that patients receive regular mental health assessments, a "team-based" approach may help patients adhere to their treatment regimen [27].

\section{Pharmacologic agents}

- Antidepressant medications: For patients with LLD and impaired cognition, the first task is to ensure adequate treatment of the depressive episode, verified by ratings on a clinical scale with validity in older adults, such as the GDS [28].

- When selecting antidepressant medications, the clinician should be aware that certain agents have the potential to impair cognition (such as agents with anticholinergic or sedative properties).

- Tricyclic antidepressants (TCAs) have anticholinergic properties that impair cognition, and their use should be avoided in older adults, whenever possible [29•] [Class IV]. Particularly challenging TCAs include amitriptyline, desipramine, imipramine, and nortriptyline.

- Selective serotonin reuptake inhibitors (SSRIs) and serotonin-norepinephrine reuptake inhibitors (SNRIs) are generally better tolerated than TCAs [30], and are associated with fewer cognitive side effects.

- Whenever possible, psychotropic polypharmacy should be avoided in older adults, to minimize the potential for drug-drug interactions, compliance errors, and overall side-effect burden [31].

- In the following section, we provide a brief review of antidepressant classes that are useful for treating LLD.

Selective serotonin reuptake inhibitors (SSRIs)

SSRIs are the preferred first-line pharmacotherapy agents for LLD. As a class, the SSRIs are not associated with poorer cognitive performance, and may even slightly improve cognition in individuals with 
Standard dosage Varies by agent [35]. To minimize side effects, starting dose should be half of that prescribed for a younger adult. Increase dose over 1- to 2-week intervals, with a plan to reach therapeutic dosing within 4 weeks. While the average therapeutic dose is typically lower than that of a younger adult, there is a fair amount of inter-individual variability, and some older adults will require doses that meet or exceed the average therapeutic dose for younger adults [34].

Contraindications Relatively few, apart from recent or current treatment with agents that increase risk for serotonin syndrome. Monitor sodium level in patients with history of hyponatremia.

Main drug interactions Must avoid simultaneous treatment with MAO inhibitors. Escitalopram, citalopram, and sertraline are considered "cleaner" SSRIs, with fewer drugdrug interactions. "Dirtier" SSRIs include fluoxetine, paroxetine, and fluvoxamine, due to greater potential for drug-drug interactions [34].

Main side effects Nausea, diarrhea, insomnia, sexual dysfunction, agitation, restlessness, and daytime sedation, among others.

Special points Special caution must be used with citalopram, given the risk for QT prolongation among adults older than 60. In this population, the maximum FDA-approved dose for citalopram is $20 \mathrm{mg} /$ day. For all SSRIs administered to the elderly, check sodium level 1 month after starting treatment, given the risk for syndrome of inappropriate antidiuretic hormone secretion (SIADH) in the elderly.

Cost-effectiveness Citalopram and sertraline are more cost-effective than escitalopram, due to the availability of generic formulations.

Serotonin-norepinephrine reuptake inhibitors (SNRIs)

The SNRIs are typically used as second-line agents for the treatment of LLD, after failure to respond to two previous SSRI monotherapy trials. The SNRI class includes duloxetine, venlafaxine, desvenlafaxine, and milnacipran (not available in the United States). As a class, the SNRIs have a slightly greater side-effect burden than the SSRIs, though they are better tolerated than the older TCAs [36].

Standard dosage Varies by agent [35]. To minimize side effects, starting dose should be half of that prescribed for a younger adult. Increase dose over 1- to 2-week intervals, with a plan to reach therapeutic dosing within 4 weeks. While the average therapeutic dose is typically lower than that of a younger adult, there is a fair amount of inter-individual variability, and some older adults will require doses that meet or exceed the average therapeutic dose for younger adults [34].

Contraindications For venlafaxine: uncontrolled hypertension, hyponatremia. 
Main drug interactions

Main side effects

Special points

Cost-effectiveness
For all SNRIs: simultaneous treatment with linezolid or an MAO-inhibiting agent. For duloxetine: avoid thioridazine due to CYP2D6 interaction. For desvenlafaxine: avoid axitinib due to CYP3A4 interaction [35].

Venlafaxine may cause noradrenergic side effects that include dry mouth, constipation, and tachycardia, as well as treatment-emergent hypertension. Abrupt discontinuation of venlafaxine may lead to symptoms such as nausea, chills, insomnia, irritability, and parasthesias. Duloxetine has a lower risk for treatment-emergent hypertension, and fewer discontinuation symptoms when treatment is terminated, but may be associated with a greater risk for liver enzyme abnormalities.

For individuals with normal hepatic metabolism, venlafaxine is primarily metabolized to O-desmethylvenlafaxine (ODV) by the enzyme CYP4502D6, and ODV plasma levels are normally two to three times higher than those of the parent drug. As a result, with the exception of patients who are "poor metabolizers" through the CYP450 2D6 system, patients who have been treated with venlafaxine have been treated (primarily) with desvenlafaxine.

The extended-release formulation of venlafaxine is considerably more expensive than the standard-release formulation, and its relatively small efficacy advantage has not been viewed as sufficient justification to offset its higher cost. Desvenlafaxine and duloxetine are not available in generic formulation, and are more expensive than standard-release venlafaxine.

\section{Add-on pharmacotherapy for the treatment of depression}

For individuals who do not respond to SSRI or SNRI monotherapy, combination pharmacotherapy may be appropriate. Widely-used combinations include the addition of an atypical antipsychotic (such as aripiprazole, risperidone, or olanzapine), bupropion (an activating antidepressant), or mirtazapine (a sedating antidepressant) to SSRI or SNRI monotherapy. Evidence-based psychotherapy (discussed below) should be used in conjunction with the above-noted pharmacotherapy strategies.

- Pharmacotherapy for cognitive enhancement: Pharmacologic augmentation with a cholinesterase inhibitor, such as donepezil, may improve cognition in certain individuals with LLD and cognitive dysfunction. As a "disease-modifying" drug, memantine has been shown to slow cognitive and functional deterioration in individuals with moderate to severe Alzheimer's disease, but this effect has not been demonstrated in individuals with milder cognitive dysfunction associated with ment, and the slowing of the dementia conversion rate-must be weighed against the risk of recurrence of major depression in those with mild cognitive impairment, the possible appearance of manic symptoms, and the potential to worsen suicidal ideation or behavior [37 $\bullet$ ] [Class I].

Standard dosage $5 \mathrm{mg}$ once daily; may increase to $10 \mathrm{mg}$ once daily after $4-6$ weeks; effective dosage range in clinical studies: $5-10 \mathrm{mg} /$ day 


\begin{tabular}{|c|c|c|}
\hline & Contraindications & No absolute contraindications \\
\hline & Main drug interactions & $\begin{array}{l}\text { May increase serum concentration of succinylcholine, and caution is advised } \\
\text { if these agents are used concurrently [35] }\end{array}$ \\
\hline & Main side effects & $\begin{array}{l}\text { Insomnia and other sleep disorders (abnormal dreams, vivid dreams, } \\
\text { nightmares), dose-related anorexia/weight loss, diarrhea, nausea, and/or } \\
\text { vomiting; may cause bradycardia or heart block in some individuals, inde- } \\
\text { pendent of their personal history of cardiac disease. Lower-weight patients } \\
(<55 \mathrm{~kg}) \text { may experience more nausea, vomiting, and weight loss compared } \\
\text { to higher-weight patients. }\end{array}$ \\
\hline & Special points & $\begin{array}{l}\text { Considered to improve "cognitive symptoms" in Alzheimer's disease, but not } \\
\text { classified as a "disease-modifying" agent. }\end{array}$ \\
\hline & Cost-effectiveness & Expensive \\
\hline & & \\
\hline & & $\begin{array}{l}\text { Memantine has been shown to slow cognitive and functional deteriora- } \\
\text { tion in individuals with moderate to severe Alzheimer's disease, but this } \\
\text { effect has not been demonstrated in individuals with cognitive dys- } \\
\text { function associated with LLD. In addition, it has been proposed that } \\
\text { memantine may exhibit antidepressant effects [38], though this has not } \\
\text { been demonstrated in human studies [39]. }\end{array}$ \\
\hline & Standard dosage & $\begin{array}{l}\text { Begin with } 5 \mathrm{mg} / \text { day, and increase by } 5 \mathrm{mg} \text { each week, to achieve target dose } \\
\text { of } 20 \mathrm{mg} / \text { day. Total daily doses }>5 \mathrm{mg} \text { daily should be given in two divided } \\
\text { doses. }\end{array}$ \\
\hline & Contraindications & $\begin{array}{l}\text { No absolute contraindications, but caution is advised in patients with car- } \\
\text { diovascular disease-clinical trial data suggest an increased incidence of } \\
\text { cardiac failure, angina, bradycardia, and hypertension, compared with pla- } \\
\text { cebo. Also, use with caution in patients with severe hepatic impairment. }\end{array}$ \\
\hline & Main drug interactions & $\begin{array}{l}\text { Monitor closely when prescribed with trimethoprim, sodium bicarbonate, or } \\
\text { carbonic anhydrase inhibitors [35] }\end{array}$ \\
\hline & Main side effects & $\begin{array}{l}\text { Generally well-tolerated; may cause dizziness, confusion, headache, som- } \\
\text { nolence or fatigue, vomiting, weight loss, and/or cough in some individuals. }\end{array}$ \\
\hline & Special points & $\begin{array}{l}\text { Currently, the only "disease-modifying" pharmacologic agent for the treat- } \\
\text { ment of Alzheimer's disease. }\end{array}$ \\
\hline & Cost-effectiveness & Expensive \\
\hline
\end{tabular}

Psychotherapy, focused on depressive symptom reduction and overall rehabilitation, has been shown to improve global outcomes in patients with LLD, and can be provided in various settings, including outpatient clinics, senior centers, and day-hospital programs [40]. While it can be challenging to utilize traditional psychotherapeutic techniques with cognitively-impaired individuals, several evidence-based psychotherapies have been adapted for use in this population, including Problem-Solving Therapy (PST) and Interpersonal Therapy (IPT). Brief Behavioral Treatment for Insomnia (BBTI), another psychotherapeutic intervention, utilizes behavioral techniques to treat sleep disturbances, which are highly prevalent in older adults with cognitive and affective disorders. While Cognitive Behavioral Ther- 
apy (CBT) is an effective and well-studied psychotherapy for adults with MDD, its utility in cognitively-impaired individuals with LLD is less clear, and we generally prefer treatment with PST, IPT, or BBTI, which may be more accessible for the older patient. If CBT is utilized for the treatment of LLD with cognitive dysfunction, modifications may be necessary [41].

\section{Problem-solving therapy (PST)}

- PST focuses on "problem-solving" skills, and is particularly helpful for treating depressed older adults with impaired cognition. PST teaches individuals to mobilize their coping resources to approach self-identified problems and exert control over them [42]. PST directs the patient to select a "problem" that he or she would like to address, teaches a method for reviewing potential solutions, and provides a directed approach for implementing an appropriate solution. Patients are typically taught these skills over 5 weeks, and then continue to practice them (under the supervision of a therapist) for an additional 8-12 weeks.

- The "problem-solving method" consists of seven steps:

- Problem orientation (how to recognize that a problem exists)

- Problem definition (breaking the problem down into concrete components)

- Goal setting (defining the preferred outcome)

- Solution generation (brainstorming solutions to reach the preferred goal)

- Decision making (selecting the most feasible and effective solution)

- Implementation (planning when and how to use the solution)

- Solution verification (evaluating the effectiveness of the solution).

- Alexopoulos and colleagues [43] designed a modified form of PST for depressed elders with executive dysfunction, in which therapists offer more structured and directed assistance during the first phase of treatment. As treatment progresses, therapists become less active and foster independent use of the problemsolving method. Therapists also employ detailed action plans, which include calling the patient to "check in," as well as involving caregivers in the treatment plan.

\section{Interpersonal psychotherapy (IPT)}

- IPT is a structured, time-limited therapy that is effective for the treatment of LLD [44].

- In the initial phase of treatment, depressive symptoms are explored and psycho-education is provided; in doing so, the patient's depressive symptoms are linked to recent interpersonal stressors. In the 
early stages of treatment, the therapist will identify one of four "problem areas" as the focus of the therapy. Potential problem areas include: complicated grief, interpersonal conflict, role-transition, and interpersonal deficits. The patient is supported as he or she works on solutions to the problem area, and it is assumed that once the patient gains mastery over one problem area, this effect will generalize to other areas as well [45].

- IPT is well-liked by elderly patients, and has been shown to be superior to usual care in patients with moderate to severe depression [45].

\section{Brief behavioral treatment for insomnia (BBTI)}

- Sleep disturbances are frequently co-morbid with affective and cognitive disorders in older adults, and are associated with reduced quality of life and greater overall disability [46•].

- While hypnotic agents such as benzodiazepines are effective for the treatment of insomnia, safety concerns for their use in older adults include cognitive impairment and increased risk for falls and fractures [46•].

- In addition to educating patients about the importance of healthy sleep, BBTI encourages the use of four primary behavioral interventions [46•] [Class I]: reduced time in bed; waking up at the same time every day, regardless of sleep duration; not going to bed unless sleepy; and not staying in bed unless asleep. These interventions are derived from sleep restriction and stimulus control techniques, and have a well-documented efficacy.

- Cognitive training and augmentation techniques [47] can be broadly divided into "internal" and "external" strategies:

- "Internal" strategies involve memory or cognitive training aimed at enhancing cognitive performance. In recent years, internet-based approaches have been developed, along with a growing body of academic literature that documents their potential efficacy. Although results vary according to the specific intervention, computerized cognitive skill training programs, on the whole, appear to positively impact cognitive performance [48], with the greatest efficacy shown for the domains of memory and visual spatial ability, and the least efficacy shown for the domains of attention and executive functioning [48].

- "External" strategies involve the use of pre-arranged physical reminders, to serve as automatic cues in the patient's environment. Three types of physical reminders are recommended [49]: 
Immediately writing things down on a "memory" notepad, calendar, or checklist. May be coupled with auditory or visual cues (e.g., an alarm that "rings" at specified times).

Placing reminders in prominent places that are in the patient's line of sight (such as on the bathroom mirror or the refrigerator).

Associating frequently-lost objects (such as keys, wallets, spectacles) with pre-established locations. The patient should practice the act of placing these objects in their designated locations.

Interventional procedures

Standard procedure

Contraindications

Complications

Cost-effectiveness
- Electroconvulsive Therapy (ECT): ECT is a safe and effective treatment for LLD [50•] [Class IV], and may be particularly useful for treating suicidal ideation and psychotic symptoms in depressed elders [51]. In healthy adult patients, ECT can result in transient cognitive side effects-such as reduced concentration, disorientation, and retrograde memory loss $[50 \bullet]$ - that typically resolve within 4 8 weeks [52]; in older adults, however, the cognitive effects of ECT are less clearly defined. Pre-treatment cognitive impairment is a strong predictor of co-occurring, and perhaps persistent, ECT-associated memory impairment [53]. Some reports have suggested that ECT does not cause long-term cognitive problems in older patients [54], though further study of this topic is warranted. From a clinical perspective, cognitive testing and monitoring must be performed before, during, and after treatment with ECT [50•].

May be provided in an inpatient or outpatient setting, though it is usually started on an inpatient basis for older adult patients. Administered either unilaterally or bilaterally, up to three times per week. While frequency and number of treatments are determined by severity of illness, response, and tolerability, most patients will complete greater than ten treatments as part of an acute-phase ECT trial.

While there are no "absolute" contraindications to the use of ECT in older adults, the greatest risk appears to exist for patients who have had a stroke, especially in the past 6 months.

Nausea, headache, muscle aches, and risks associated with general anesthesia.

While expensive, studies have suggested that ECT may result in shorter overall inpatient psychiatric hospital stays for severely depressed elderly patients [51].

- Repetitive Transcranial magnetic stimulation (rTMS): rTMS appears to be a safe and well-tolerated treatment for treatment-resistant depression in older individuals [55]. Questions remain, however, regarding its antidepressant efficacy. It appears that rTMS exhibits fewer deleterious cognitive side effects than ECT, and may even improve immediate memory in some patients [56]. For treatment-refractory depression in the elderly, ECT continues to be the gold-standard interventional procedure, though the benefits of rTMS-including the lack of need for general anesthesia, ease of treating on an outpatient 
Standard procedure Usually administered by stimulating the left dorsal lateral prefrontal cortex, 5 days/week over 4-6 weeks in an outpatient setting.

Contraindications Contraindicated in individuals at increased risk for seizures, those with implanted metallic or cochlear implants, and individuals with other implanted electrical devices (such as pacemakers).

Complications The most serious complication is generalized tonic-clonic seizures.

Special points For treatment of LLD, rTMS appears to be less efficacious than ECT.

Cost-effectiveness Expensive

\section{Assistive devices}

- As hearing or visual impairment may be mistaken for cognitive dysfunction, hearing should be assessed by an audiologist, and vision should be assessed by an ophthalmologist or optometrist, with corrective actions implemented as necessary.

- We highly recommend the use of a pillbox to organize medications. The pillbox should be filled on a regular weekly or monthly schedule, preferably with the assistance of a caregiver.

\section{Physical/speech therapy and exercise}

- Physical and Occupational therapy

- Physical therapists can assess the need for a wheelchair or walking aid, as well as recommend or guide the implementation of an exercise program.

- Occupational therapists can evaluate the patient's home for safety, and assess the need for assistive devices.

- Exercise

- Exercise has been shown to have antidepressant effects in the elderly [57], even in individuals who respond poorly to antidepressant medications [58].

- Cardiovascular (i.e., aerobic) exercise may be particularly helpful, and has the potential to maintain or improve cognitive health and functioning in older adults [59].

- Deep brain stimulation (DBS)

- In recent years, DBS has emerged as a useful treatment for certain movement disorders, and is being investigated for the treatment of other neuropsychiatric conditions, including depression and dementia. 
Several studies have investigated DBS for dementia, and have shown that DBS can influence neuronal activity within pathologic circuits associated with cognitive dysfunction [60] and potentially produce clinical benefits by enhancing the synthesis of nerve growth factors [61]. For treatment-resistant depression, DBS may be helpful in targeting white matter tracts adjacent to the subgenual cingulate gyrus, an area that is metabolically hyperactive in individuals with this disorder [62, 63].

- DBS is a circuit-specific intervention that may have fewer cognitivelyadverse effects than ECT, and could possibly even enhance cognition. It has been proposed that potential pro-cognitive effects of DBS may be enhanced by combining stimulation with another intervention, such as cognitive remediation [64].

- Vagal nerve stimulation (VNS)

- Vagal nerve stimulation is currently used as an adjunctive intervention for refractory epilepsy and treatment-resistant depression. VNS requires a surgical procedure to attach an electrode around the vagal nerve, which is then connected to a pulse generator in the chest. While VNS is effective for the treatment of refractory epilepsy-especially in the pediatric population-and has been used for treatment-resistant depression, there is currently no data to support its use in LLD with cognitive dysfunction. The results of an open-label, pilot trial suggest a positive effect of VNS on cognition in patients with Alzheimer's disease, though further studies are required [65].

- Magnetic seizure therapy (MST)

MST is a promising experimental therapy for depression [66], and involves the induction of a seizure through the use of magnetic stimulation. MST is less invasive than ECT, and because magnetic fields are able to pass freely into the brain, MST is able to induce a more focal seizure compared with ECT. MST targets stimulation to the prefrontal cortex (a region of the brain that is thought to be critical for antidepressant response), and limits exposure to the hippocampus (a region of the brain that is important for memory). Therefore, MST holds the promise of retaining the efficacy of ECT while limiting the side-effect burden.

\section{Compliance with ethics guidelines}

\section{Conflict of Interest}

In the past year, Aaron M. Koenig has received financial support from the APIRE/Janssen Resident Psychiatric Research Scholars program.

In the past year, Meryl A. Butters has received grant support from the National Institute of Mental Health (R01s $072947 \&$ 080240) and has received remuneration from GlaxoSmithKline for neuropsychological services.

Human and Animal Rights and Informed Consent

This article does not contain any studies with animal subjects performed by any of the authors. 


\section{References and Recommended Reading}

Papers of particular interest, published recently, have been highlighted as:

- $\quad$ Of importance

1. Butters MA, Whyte EM, Nebes RD, Begley AE, Dew $\mathrm{MA}$, Mulsant $\mathrm{BH}$, et al. The nature and determinants of neuropsychological functioning in late-life depression. Arch Gen Psychiatry. 2004;61(6):587-95. doi:10.1001/archpsyc.61.6.587.

2. Sheline YI, Barch DM, Garcia K, Gersing K, Pieper C, Welsh-Bohmer $\mathrm{K}$, et al. Cognitive function in late life depression: relationships to depression severity, cerebrovascular risk factors and processing speed. Biol Psychiatry. 2006;60(1):58-65. doi:10.1016/ j.biopsych.2005.09.019.

3. Nebes RD, Butters MA, Mulsant BH, Pollock BG, Zmuda MD, Houck PR, et al. Decreased working memory and processing speed mediate cognitive impairment in geriatric depression. Psychol Med. 2000;30(3):679-91.

4. Lockwood KA, Alexopoulos GS, van Gorp WG. Executive dysfunction in geriatric depression. Am J Psychiatry. 2002;159(7):1119-26.

5. Baudic S, Tzortzis C, Barba GD, Traykov L. Executive deficits in elderly patients with major unipolar depression. J Geriatr Psychiatry Neurol. 2004;17(4):195-201. doi:10.1177/ 0891988704269823.

6. Elderkin-Thompson V, Kumar A, Bilker WB, Dunkin JJ, Mintz J, Moberg PJ, et al. Neuropsychological deficits among patients with late-onset minor and major depression. Arch Clin Neuropsychol Off J Natl Acad Neuropsychol. 2003;18(5):529-49.

7. Rapp MA, Dahlman K, Sano M, Grossman HT, Haroutunian V, Gorman JM. Neuropsychological differences between late-onset and recurrent geriatric major depression. Am J Psychiatry. 2005;162(4):691-8. doi:10.1176/appi.ajp.162.4.691.

8. Reynolds 3rd CF, Alexopoulos GS, Katz IR, Lebowitz BD. Chronic depression in the elderly: approaches for prevention. Drugs Aging. 2001;18(7):507-14

9. Gallo JJ, Rabins PV, Lyketsos CG, Tien AY, Anthony JC. Depression without sadness: functional outcomes of nondysphoric depression in later life. J Am Geriatr Soc. 1997;45(5):570-8.

10. Hegeman JM, Kok RM, van der Mast RC, Giltay EJ. Phenomenology of depression in older compared with younger adults: meta-analysis. Br J Psychiatry. 2012;200(4):275-81. doi:10.1192/ bjp.bp.111.095950.

11. Steffens DC, Fisher GG, Langa KM, Potter GG, Plassman BL. Prevalence of depression among older Americans: the aging, demographics and memory study. Int Psychogeriatr IPA. 2009;21(5):879-88. doi:10.1017/S1041610209990044.
12. Blazer DG. Depression in late life: review and commentary. J Gerontol Ser A Biol Sci Med Sci. 2003;58(3):249-65.

13. Steffens DC, Otey E, Alexopoulos GS, Butters MA, Cuthbert B, Ganguli M, et al. Perspectives on depression, mild cognitive impairment, and cognitive decline. Arch Gen Psychiatry. 2006;63(2):130-8. doi:10.1001/archpsyc.63.2.130.

14. Beekman AT, Penninx BW, Deeg DJ, de Beurs E, Geerling SW, van Tilburg W. The impact of depression on the well-being, disability and use of services in older adults: a longitudinal perspective. Acta Psychiatr Scand. 2002;105(1):20-7.

15. Bruce ML, Ten Have TR, Reynolds 3rd CF, Katz II, Schulberg HC, Mulsant BH, et al. Reducing suicidal ideation and depressive symptoms in depressed older primary care patients: a randomized controlled trial. JAMA. 2004;291(9):1081-91. doi:10.1001/ jama.291.9.1081.

16. Doraiswamy PM, Krishnan KR, Oxman T, Jenkyn LR, Coffey DJ, Burt T, et al. Does antidepressant therapy improve cognition in elderly depressed patients? The Journals of Gerontology Series A. Biol Sci Med Sci. 2003;58(12):M1137-44.

17. Bhalla RK, Butters MA, Mulsant BH, Begley AE, Zmuda MD, Schoderbek B, et al. Persistence of neuropsychologic deficits in the remitted state of late-life depression. Am J Geriatr Psychiatr Off J Am Assoc Geriatr Psychiatry. 2006;14(5):419-27. doi:10.1097/01.JGP.0000203130.45421.69.

18. Butters MA, Becker JT, Nebes RD, Zmuda MD, Mulsant BH, Pollock BG, et al. Changes in cognitive functioning following treatment of latelife depression. Am J Psychiatry. 2000;157(12):1949-54.

19. Nebes RD, Pollock BG, Houck PR, Butters MA, Mulsant $\mathrm{BH}, \mathrm{Zmuda} \mathrm{MD}$, et al. Persistence of cognitive impairment in geriatric patients following antidepressant treatment: a randomized, double-blind clinical trial with nortriptyline and paroxetine. $J$ Psychiatr Res. 2003;37(2):99-108.

20. Murphy CF, Alexopoulos GS. Longitudinal association of initiation/perseveration and severity of geriatric depression. Am J Geriatr Psychiatr Off J Am Assoc Geriatr Psychiatry. 2004;12(1):50-6.

21. Lee JS, Potter GG, Wagner HR, Welsh-Bohmer KA, Steffens DC. Persistent mild cognitive impairment in geriatric depression. Int Psychogeriatr IPA. 2007;19(1):125-35. doi:10.1017/ S1041610206003607.

22. Bhalla RK, Butters MA, Becker JT, Houck PR, Snitz BE, Lopez OL, et al. Patterns of mild cognitive impairment 
after treatment of depression in the elderly. Am J Geriatr Psychiatr Off J Am Assoc Geriatr Psychiatry.

2009;17(4):308-16. doi:10.1097/

JGP.0b013e318190b8d8.

23. Barch DM, D'Angelo G, Pieper C, Wilkins CH, WelshBohmer K, Taylor W, et al. Cognitive improvement following treatment in late-life depression: relationship to vascular risk and age of onset. Am J Geriatr Psychiatr Off J Am Assoc Geriatr Psychiatry. 2012;20(8):682-90. doi:10.1097/ JGP.0b013e318246b6cb.

24. Adler G, Rottunda S, Dysken M. The older driver with dementia: an updated literature review. J Saf Res. 2005;36(4):399-407. doi:10.1016/j.jsr.2005.07.005.

25. Snyder CH. Dementia and driving: autonomy versus safety. J Am Acad Nurse Pract. 2005;17(10):393-402. doi:10.1111/j.1745-7599.2005.00070.x.

26. Vance D, Larsen KI, Eagerton G, Wright MA. Comorbidities and cognitive functioning: implications for nursing research and practice. J Neurosci Nurs J Am Assoc Neurosci Nurses. 2011;43(4):215-24. doi:10.1097/JNN.0b013e3182212a04.

27. Alexopoulos GS, Reynolds 3rd CF, Bruce ML, Katz IR, Raue PJ, Mulsant BH, et al. Reducing suicidal ideation and depression in older primary care patients: 24-month outcomes of the PROSPECT study. Am J Psychiatry. 2009;166(8):882-90. doi:10.1176/ appi.ajp.2009.08121779.

28. Yesavage JA, Brink TL, Rose TL, Lum O, Huang V, Adey $\mathrm{M}$, et al. Development and validation of a geriatric depression screening scale: a preliminary report. J Psychiatr Res. 1982;17(1):37-49.

29. American Geriatrics Society updated Beers Criteria for potentially inappropriate medication use in older adults. J Am Geriatr Soc. 2012;60(4):616-31. doi:10.1111/j.1532-5415.2012.03923.x.

[Class IV] This article reports on a recent update to the Beers Criteria, highlighting medications that are potentially inappropriate for use in older adults

30. Mottram P, Wilson K, Strobl J. Antidepressants for depressed elderly. Cochrane Database Syst Rev. 2006;1, CD003491. doi:10.1002/ 14651858.CD003491.pub2.

31. Tsai KT, Chen JH, Wen CJ, Kuo HK, Lu IS, Chiu LS, et al. Medication adherence among geriatric outpatients prescribed multiple medications. Am J Geriatr Pharmacother. 2012;10(1):61-8. doi:10.1016/ j.amjopharm.2011.11.005.

32. Han L, McCusker J, Cole M, Capek R, Abrahamowicz $\mathrm{M}$. Antidepressant use and cognitive functioning in older medical patients with major or minor depression: a prospective cohort study with database linkage. J Clin Psychopharmacol. 2011;31(4):429-35. doi:10.1097/JCP.0b013e318221b2f8.

33. Koenig AM, Thase ME. First-line pharmacotherapies for depression - what is the best choice? Pol Arch Med Wewn. 2009;119(7-8):478-86.
34. Wiese B. Geriatric depression: the use of antidepressants in the elderly. BCMJ. 2011;53(7):341-7.

35. Lexicomp Online [database on the Internet]. LexiComp, Inc. 2013. Accessed: 9-20-13.

36. Mukai Y, Tampi RR. Treatment of depression in the elderly: a review of the recent literature on the efficacy of single- versus dual-action antidepressants. Clin Ther. 2009;31(5):945-61. doi:10.1016/ j.clinthera.2009.05.016.

37. Reynolds III CF, Butters MA, Lopez O, Pollock BG, Dew MA, Mulsant BH, et al. Maintenance treatment of depression in old age: a randomized, doubleblind, placebo-controlled evaluation of the efficacy and safety of donepezil combined with antidepressant pharmacotherapy. Arch Gen Psychiatry. 2011;68(1):51-60. doi:10.1001/ archgenpsychiatry.2010.184.

[Class I] This article reports the main outcomes from the MTLD-3 study, an RCT that examined whether donepezil and antidepressant therapy was superior to placebo and antidepressant therapy in improving cognitive performance and reducing depression recurrent over 2 years of maintenance treatment

38. Quan MN, Zhang N, Wang YY, Zhang T, Yang Z. Possible antidepressant effects and mechanisms of memantine in behaviors and synaptic plasticity of a depression rat model. Neuroscience. 2011;182:88-97. doi:10.1016/j.neuroscience.2011.03.026.

39. Lenze EJ, Skidmore ER, Begley AE, Newcomer JW, Butters MA, Whyte EM. Memantine for late-life depression and apathy after a disabling medical event: a 12-week, double-blind placebo-controlled pilot study. Int J Geriatr Psychiatr. 2012;27(9):974-80. doi:10.1002/gps.2813.

40. Alexopoulos GS, Vrontou C, Kakuma T, Meyers BS, Young RC, Klausner E, et al. Disability in geriatric depression. Am J Psychiatry. 1996;153(7):877-85.

41. Thompson LW. Cognitive-behavioral therapy and treatment for late-life depression. J Clin Psychiatry. 1996;57 Suppl 5:29-37.

42. Arean PA, Perri MG, Nezu AM, Schein RL, Christopher F, Joseph TX. Comparative effectiveness of social problem-solving therapy and reminiscence therapy as treatments for depression in older adults. $J$ Consult Clin Psychol. 1993;61(6):1003-10.

43. Alexopoulos GS, Raue PJ, Kanellopoulos D, Mackin $\mathrm{S}$, Arean PA. Problem solving therapy for the depression-executive dysfunction syndrome of late life. Int J Geriatr Psychiatr. 2008;23(8):782-8. doi:10.1002/gps.1988.

44. Miller MD, Cornes C, Frank E, Ehrenpreis L, Silberman $\mathrm{R}$, Schlernitzauer MA, et al. Interpersonal psychotherapy for late-life depression: past, present, and future. J Psychother Pract Res. 2001;10(4):231-8.

45. van Schaik DJ, van Marwijk HW, Beekman AT, de Haan M, van Dyck R. Interpersonal psychotherapy (IPT) for late-life depression in general practice: uptake 
and satisfaction by patients, therapists and physicians. BMC family practice. 2007;8:52.

doi:10.1186/1471-2296-8-52.

46. Buysse DJ, Germain A, Moul DE, Franzen PL, Brar LK, Fletcher ME, et al. Efficacy of brief behavioral treatment for chronic insomnia in older adults. Arch Intern Med. 2011;171(10):887-95. doi:10.1001/ archinternmed.2010.535.

[Class I] This article reports the outcomes of a randomized trial of brief behavioral treatment for insomnia (BBTI), and demonstrates that BBTI is a simple, efficacious, and durable intervention for chronic insomnia in older adults

47. Fava GA, Ruini C, Sonino N. Treatment of recurrent depression: a sequential psychotherapeutic and psychopharmacological approach. CNS Drugs.

2003;17(15):1109-17.

48. Kueider AM, Parisi JM, Gross AL, Rebok GW. Computerized cognitive training with older adults: a systematic review. PLoS ONE. 2012;7(7):e40588. doi:10.1371/journal.pone.0040588.

49. Scogin FR, Prohaska M. Aiding older adults with memory complaints. Practitioner's resource series. Sarasota: Professional Resource Press; 1993.

50. Oudman E. Is electroconvulsive therapy (ECT) effective and safe for treatment of depression in dementia? A short review. J ECT. 2012;28(1):34-8. doi:10.1097/YCT.0b013e31823a0f5a.

[Class IV] This literature review provides a critical analysis of the efficacy and safety of ECT for the treatment of depression with dementia

51. Dombrovski AY, Mulsant BH. The evidence for electroconvulsive therapy (ECT) in the treatment of severe late-life depression. ECT: the preferred treatment for severe depression in late life. Int Psychogeriatr IPA. 2007;19(1):10-4. doi:10.1017/

S1041610206224384. 27-35; discussion 24-6.

52. Semkovska M, McLoughlin DM. Objective cognitive performance associated with electroconvulsive therapy for depression: a systematic review and metaanalysis. Biol Psychiatry. 2010;68(6):568-77. doi:10.1016/j.biopsych.2010.06.009.

53. Sobin C, Sackeim HA, Prudic J, Devanand DP, Moody BJ, McElhiney MC. Predictors of retrograde amnesia following ECT. Am J Psychiatry. 1995;152(7):995-1001.

54. Hausner L, Damian M, Sartorius A, Frolich L. Efficacy and cognitive side effects of electroconvulsive therapy (ECT) in depressed elderly inpatients with coexisting mild cognitive impairment or dementia. $J$ Clin Psychiatry. 2011;72(1):91-7. doi:10.4088/ JCP.10m05973gry.

55. Hizli Sayar G, Ozten E, Tan O, Tarhan N. Transcranial magnetic stimulation for treating depression in elderly patients. Neuropsychiatr Dis Treat. 2013;9:501-4. doi:10.2147/NDT.S44241.

56. Kedzior KK, Rajput V, Price G, Lee J, Martin-Iverson $M$. Cognitive correlates of repetitive transcranial magnetic stimulation (rTMS) in treatment-resistant depression-a pilot study. BMC Psychiatry. 2012;12:163. doi:10.1186/1471-244X-12-163.

57. Singh NA, Clements KM, Singh MA. The efficacy of exercise as a long-term antidepressant in elderly subjects: a randomized, controlled trial. J Gerontol Ser A Biol Sci Med Sci. 2001;56(8):M497-504.

58. Mather AS, Rodriguez C, Guthrie MF, McHarg AM, Reid IC, McMurdo ME. Effects of exercise on depressive symptoms in older adults with poorly responsive depressive disorder: randomised controlled trial. Br J Psychiatry. 2002;180:411-5.

59. Gregory MA, Gill DP, Petrella RJ. Brain health and exercise in older adults. Curr Sports Med Rep.

2013;12(4):256-71. doi:10.1249/ JSR.0b013e31829a74fd.

60. Laxton AW, Lozano AM. Deep brain stimulation for the treatment of Alzheimer disease and Dementias. World Neurosurg. 2012. doi:10.1016/ j.wneu.2012.06.028.

61. Hardenacke K, Kuhn J, Lenartz D, Maarouf M, Mai JK, Bartsch C, et al. Stimulate or degenerate: deep brain stimulation of the nucleus basalis Meynert in Alzheimer Dementia. World Neurosurg. 2012. doi:10.1016/j.wneu.2012.12.005.

62. Mayberg HS, Lozano AM, Voon V, McNeely HE, Seminowicz D, Hamani C, et al. Deep brain stimulation for treatment-resistant depression. Neuron. 2005;45(5):651-60. doi:10.1016/j.neuron. 2005.02.014.

63. Holtzheimer PE, Kelley ME, Gross RE, Filkowski MM, Garlow SJ, Barrocas A, et al. Subcallosal cingulate deep brain stimulation for treatment-resistant unipolar and bipolar depression. Arch Gen Psychiatry. 2012;69(2):150-8. doi:10.1001/ archgenpsychiatry.2011.1456.

64. Liu AY, Rajji TK, Blumberger DM, Daskalakis ZJ, Mulsant $\mathrm{BH}$. Brain stimulation in the treatment of late-life severe mental illness other than unipolar nonpsychotic depression. Am J Geriatr Psychiatr Off J Am Assoc Geriatr Psychiatry. 2013. doi:10.1016/j.jagp.2013.02.017.

65. Sjogren MJ, Hellstrom PT, Jonsson MA, Runnerstam M, Silander HC, Ben-Menachem E. Cognition-enhancing effect of vagus nerve stimulation in patients with Alzheimer's disease: a pilot study. J Clin Psychiatry. 2002;63(11):972-80.

66. Alexopoulos GS, Kelly Jr RE. Research advances in geriatric depression. World Psychiatry. 2009;8(3):140-9. 